\title{
SCIENCE AND FAITH.
}

\author{
I. MAN AS AN ANIMAL.
}

TN THE year 1878, in the course of the first Exposition of Anthropological Sciences at Paris, I became engaged in a controversy with a celebrated Dominican, Père Didon, on the irreconcilability of science and faith. In 1893 , in a memoir which appeared in $L^{\prime}$ Anthropologie, ${ }^{1} I$ broached the conclusion that man as animal and man as a member of society were contradictory, that society was a compromise between the truths of science and the necessities of practical conduct, and that to establish firmly the foundations of ethics, it was necessary to admit as dogmas, or articles of faith, which should be exempt from discussion, certain principles that were implied in all social solidarity, such as justice, the distinction of good from evil, altruism, etc.

These conclusions were distressing to me. I have not ceased since to ponder on them. I have searched for some property of living beings possessing or not possessing a nervous system that would give body and objective reality to these dogmas. I have reread the beautiful pages of Herbert Spencer and other philosophers on the subject. I have devoted my best attention to Guyau and Fouillee's "ethics without obligation and without sanction." I have read the works of Dr. Paul Carus, his Probleme de la conscience du moi, which has been translated into French in the Library of Contemporary Philosophy, the lectures which he delivered at the Congress of Religions during the recent World's Fair in Chicago,

1 Paul Topinard, "Quelques conclusions et appications de l'anthropologie," in L'Anthropologic, 1893 , pp. 657-696. 
his Primer of Philosophy, etc. The doctrine which Dr. Carus upholds in The Monist and The Open Court is seductive. It may be that a better one cannot be found. It is ingenious and accords perfectly in its premises with the facts of science. But it swerves aside in its applications. The spirit which conceived the first part is not maintained in the second; the seam is visible. Will this doctrine convert the masses, which it is our aim to lead into the ways of righteousness? Will it prove sufficient as a sanction of the moral obligation? That is the question.

We are among scholars. We are seeking in the same paths. We are in accord as to the object aimed at. Let us then be clear.

The first thing requisite is to bring matters scientifically to a head, to look the enemy squarely and fearlessly in the face, and to let the truth stand forth in its full entirety and nakedness. It is necessary, therefore, to recall what we know about man and societies, that is, to ascertain what is the upshot of the final data of the science of anthropology. The field is vast-too vast to be traversed, even hurriedly, in its whole extent. But there are parts of more importance than others, and of these I may be permitted to give a brief recapitulation.

Anthropology, in its broad sense, comprises everything that relates to man, and is divided into anthropology in its restricted sense, or anthropology proper, and into ethnical anthropology. The former studies man as an animal, first the individual, then the principal varieties called races, ${ }^{1}$ and lastly the species in its relation to other species-all three in the double point of view of morphology and biology. The second studies men as associated together in peoples, tribes, civilisations, and societies, and that in all points of view, as to distribution into different epochs, history and prehistory, modes of life, habitat, alimentation, industry, manners and

\footnotetext{
${ }^{1}$ Races are permanent varieties of the species, I say. They should not be confounded with peoples or with languages. Races belong to the province of the anthropological naturalist, and can be extricated from the peoples among which they are mingled only by the special knowledge and methods of the naturalist. The word should never be used in ethnical anthropology.
} 
customs, languages, religions, arts and letters, institutions and ideas, morality, etc., and their evolution from the past to the present; it is divided into ethnology ${ }^{1}$ and sociology.

I have long admitted a third division of anthropology for moral or psychical man. Reason being the highest attribute of man, it seemed to me expedient to assign to man a place apart, were it only for the purpose of applying here certain methods not employed in the other two divisions. But the elements of which this third division is composed require to be examined alternately in man as an animal and in man as a member of society. In this phase of my scientific ontogeny I said that anthropology had three objects of study, animal man, mental man, and social man. To-day I see drawbacks to this division and reduce the objects of anthropological study to two only: animal man and social man.

Anthropology, in the restricted sense, is the anthropology of Blumenbach and of the French school. It belongs to the department of the naturalist, or of the physician with the training of a naturalist. It thus embraces all that the natural history of an animal involves, and is distinguished by no special feature except the very extensive scope of certain of its chapters. The knowledge which it necessitates is derived from three sources: ( 1 ) the knowledge which the naturalist acquires concerning all organised beings, particularly animals, but notably Vertebrates, Mammals, and Primates, and which he applies as his taste dictates to this or to that animal; (2) the knowledge which the physician acquires, anatomy, physiology, pathology, embryogeny, teratology, mesology, etc.; (3) the knowledge which the anthropologist reserves for his own proper domain, and which relates to the two following grand subjects about which all his researches turn:

$A$. Human races in the present and past, their origin, relationship, and history.

II should not have employed this word if I were writing for France, because it was wrested from its legitimate meaning sixty years ago by $W$. Edwards. He took it as synonymous with the natural history of races, whilst it designates the general history of nations. 
$B$. The human species, its various characters, its place in the zoölogical classifications, its genealogy.

We shall pass over the races and speak only of the species. To be sure, classifications are only "artificial expedients," to use an expression of Lamarck, or "subjective conceptions to which no absolute demarcation corresponds in nature," to use the words of Herbert Spencer. Nevertheless, they express and sum up the state of our knowledge, and that is precisely what we want. Classifications, not systematic but natural, give a succinct tableau of the common characters or resemblances that animals present, whether of the primary, secondary, tertiary, or other order, corresponding to groups more or less circumscribed, called divisions, classes, orders, families, genera, etc.-and of the particular characters or differences which distinguish each of the included divisions of these groups. To give a place to man in the classification means to strike the balance of his resemblances and differences with the different animals, to decide upon the distance which separates him from the nearest members of his special group, and lastly, to assign to him his hierarchical position in the animal scale. This is what we shall now attempt to do.

First of all, man is a Vertebrate, because, like all animals comprised in this division, he possesses an internal skeleton, the fundamental constituent of which is a chain of vertebræ (or better a dorsal cord, the point of departure of this chain) provided at the front and back with costiform arches which separate the body into two cavities, one anterior, for the viscera, and one posterior, for the cerebrospinal system. Secondly, man is a Mammal, because, like all animals of this class, he has breasts, hair, a neck, four members, a corpus callosum, a heart with four chambers, a complete diaphragm, two occipital condyles, etc. Lastly, man is a Primate, because, like all other accredited animals of this order, he possesses a special type of brain characterised by the absence of the limbic lobe of other terrestrial mammals, by a prominent frontal lobe, by a parietal, a temporal, and an occipital lobe, by a peculiar system of convolutions, and by a cerebellum covered by the hemispheres; because he has a type of skull no less special, characterised by the 
rounded form of the occipital part, by developed frontal fossæ, by eye-sockets closed at the back, near to each other, and pointing forwards, by an os planum, by a mandible, of which the two parts are fused at birth, etc.; because he possesses an anterior member more or less adapted for prehension, a fore arm capable of movements of pronation and supination, a hand, that is, long and slender fingers, a thumb relatively short and opposite to the other fingers, a small and exceedingly mobile wrist; because he has three kinds of teeth with omnivorous molars, flat nails on the hands and feet, two pectoral mammæ, a unilocular uterus, a discoid placenta, a simple stomach, etc.

The Primates include the Lemurs, or semi-apes, sketch-plans of the Primates, and transitional links from the Insectivora (which were undoubtedly without placentæ) to the real Apes; the Apes, or Primates proper, comprising the Arctopitheci, a small family belonging to the New World, the Cebidæ or common monkeys of the New World, the Pitheci or tailed monkeys of the Old World, and the Anthropoids, or Apes without tails, also of the Old World.

What position does man occupy in this group of animals? Which does he most resemble? Does his distance from the nearest make of him a suborder, a tribe, a family, or perhaps a genus? Hitherto we have spoken only of the characters which are common to man and to the other animals. We have now to speak of their differences.

These differences in man as compared with the Apes have been sought for with the greatest care in all parts of the body. We no longer live in the time of Galen when to learn the anatomy of man the Barbary ape principally was dissected. We notice to-day the most unobtrusive characters, such as we should never pay attention to, were it not that they concern our own species. It happens thus that the differences in question are exceedingly numerous but reducible to a few of primary importance. In the skull, for example, craniometry furnishes at least twenty, which are reducible to three. In the skeleton, the muscles and the viscera, there are more than thirty worthy of notice, but all reducible to one. Let us examine the most important. 
But first a remark. To determine the distance which separates several species or groups of species, that is, their degree of unlikeness, their mean specific types must be considered, and not, as is sometimes done, their extreme individual variations. By the last method, the characteristic differences are submerged, and in general we arrive at a graduated but continuous series in which the lines of demarcation disappear, as Herbert Spencer has said $a$ propos of this question. The method of mean types alone exhibits the intervals sought.

Another remark. To solve our problem we are obliged to proceed analytically, that is, we must take up the characters one by one and construct from their gradations in the different species, a scale which admits of its appropriate conclusions. Now these conclusions are sometimes contradictory. The truth can be extricated only from their combination, otherwise called their synthesis.

The first characters distinguishing man from his nearest animal neighbors, relate to the cerebral nervous system. Let us hurriedly follow its developments. At the bottom of the invertebrate scale a few fibres and nervous cells are discoverable, at first dispersed. Then aggregations of cells or ganglia appear, among which are easily noticeable those consecrated to the special senses, at the point where the cephalic extremity is constituted. In this last place they approach each other in pairs with a tendency to fuse. Thus the brain takes its origin. In the lowest vertebrates it is represented by a succession of swellings or lobes having their seat on the pro. longation of the spinal cord. The largest are the olfactory and optical lobes, the smallest are the future hemispheres. Soon the rôles of the parts are reversed, the rudimentary hemispheres grow larger, expand in all directions, cover and envelop the lobes beneath and end at the summit of the scale by constituting alone almost all of the brain. The grey cortical substance, which is the essential part of the brain, finds thus an extensive surface, which ultimately not sufficing for the demands made upon it folds and refolds upon itself and by this ingenious artifice is increased in extent still more. The results are the cerebral convolutions. The folding takes different directions, and affects different types in the different classes of mam- 
mals. In the Primates it grows together with the increase of volume. The hemispheres, divided, as has been said, into four lobes, end at the back by running over the cerebellum, and in front by hanging over the face. The hemispheres efface the last traces of the limbic lobe, and by a final leap attain in man their highest degree of complexity. In this last respect there is only a difference of quantity, which is not striking, between the anthropoids and man. If we place on a table by the side of each other two brains, the one of an orang, for example, and the other of a man, we should recognise the latter, apart from its volume, only by the asymmetry of the lateral convolutions, by their smaller size, as also by their number and by their sinuosities, especially of the third frontal convolution, that of language.

As to volume the difference is striking. The brain of man is larger than that of three large anthropoids, both in relation to volume of body and to volume of skull, and absolutely in that its mean weight is treble that of the anthropoid brain.

Next to the differences between man and animals exhibited by the nervous system, come those which concern the organs of locomotion. All the members are locomotor in their origin; prehension of objects being performed directly with the mouth. From the first steps of Reptiles on solid earth the members are seen to become differentiated in a definite manner. When they creep along the fore members grasp the soil and pull the body, the hind members brace themselves against the soil and push the body. The fore members act as prehensile organs, the hind members as locomotor organs, par excellence. Both, thus, acquire distinctive initial characters which they never relinquish. Later, in the Mammals, the adaptation varies with the mode of life, the needs, and the habits. Excepting man and some aquatic species, the mammals are essentially quadrupeds, but in different degrees. In the Marsupials generally, the anterior members are utilised as organs of prehension; among some, the posterior extremities are organised as hands. In the Ungulates, or hoofed animals, the adaptation is exclusively quadruped. In the Unguiculates the anterior members serve accessorily for prehension. In the lower Primates, which are ordinary 
arboricole animals, the necessity of clinging to branches develops the function of prehension in the anterior members, or in some species in the posterior members. In the middle Primates, or Monkeys, the adaptation to arboreal life is perfected and increased in all four members. They are at once quadrupeds and quadrumanes; the entire body is in unison; they are expert gymnasts, running from limb to limb, shooting backwards and forwards, and hanging downwards by their four extremities and by their tail, which in $\mathrm{Ce}$ bidæ is prehensile. Their forehead is the most advanced product of adaptation in this direction which the animal scale has yet shown. Their posterior hand is still a foot, but modified in the direction of a hand. In the Anthropoids the same is also true, except that the posterior hand resembles more a pair of pincers with curved tongs, and that the tail has disappeared. In man, adaptation has restored the original character of the four members. The anterior members have become fixed in the direction begun in the monkeys; the posterior members have abandoned absolutely that tendency and are entirely adapted to the locomotor function. Man is the only perfect bipedal adaptation, excepting birds, that the animal kingdom presents, just as the Cervidæ are, not the only, but the most perfect adaptation of the quadruped attitude and gait. ${ }^{1}$

This brings us to the second group of characters which distinguish man from monkeys-namely, to the erect attitude which is peculiar to man. Monkeys, we have just said, are arboricole animals, marvellously adapted to their mode of existence. Their body is light, their vertebral column is supple, their members are long, slender, and mobile, their four extremities furnished with hands. On the ground they walk awkwardly on all fours. They stand erect sometimes by seeking a point of support with their fore hands on a tree or a rock. Some Pitheci and Cebidæ even show in their viscera indications of adaptation to this last occasional attitude. Some Cynocephali show traces of it also in the vertebral column. In the Anthropoids, two of which have a comparatively heavy gait, walk-

${ }^{1}$ See P. Topinard, L'homme dans la nature, Chap. VIII., Paris, 1893. Bibliothèque Scientifique Internationale. F, Alcan. 
ing on the ground is more frequent. They walk in a half-bent position, supporting themselves on the dorsal surface of the fingers and the outer edges of the feet. Do they straighten up often? In any case, the adaptation to this straightening up has produced a marked advance in the viscera, in the vertebral column, and particularly in the pelvis. As an offset, the head and the lower members have made none. In the pelvis the anthropoid approaches very near to man. In the foot he is radically different from man; in fact, he is more simian, more monkey-like, than the other Apes. The foot, the calcaneum, and the astragalus fold inwards upon the tibia, so that the sole of the foot can apply itself laterally to the trunk of a tree in climbing; the first toe, which is short in comparison with the other toes, but slender, is widely separated from the others, and plays less the part of a finger with the power to oppose the others, than that of a pincers enveloping the limb and running to meet there the other fingers, which are long and recurved.

Man himself is terricole in habits, with vertical carriage, and walking on two feet. In all parts of his body he is marvellously adapted to this mode of life. His head rests in equilibrium upon his vertebral column without effort. He has not the large posterior cervical ligament which prevents the head from falling forwards in other mammals. His vertebral column is solid, with a double dorsolumbar curvature, and is larger in the lumbar region, so as to fit firmly into an enlarged pelvis. Everything in the lower members is arranged to support the weight of the body. The tibio-tarsal mortise permits only exact movements of extension and flexion. All the bones of the tarsus are heavy and strong. The axis of the tibia, the vertical axis of the astragalus, the antero-posterior axis of the calcaneum, the axis of the foot, are all in the same plane. The first toe is large, almost of the same length as the second, and parallel to it. Its cuneo-metatarsal articulation is an arthrodia which permits neither adduction nor abduction. The sole of the foot is arched and rests solidly on the ground at three points. The foot of man is a masterpiece of adaptiveness to the vertical attitude, and the opposite of that presented by the Monkeys: Pitheci, Cebidæ, or Anthropoids. 
The characters derived from the differences of attitude furnish, accordingly, contradictory arguments; one group putting man in the same family with the Anthropoids (the pelvis, vertebral column, and viscera), the other placing him in a different order (the foot). In my opinion the latter factor is more potent.

The other differences to be noted are not of such great importance. They are such as come from the gradual perfection which takes place in the adaptation of the upper members to the function of prehension, commenced in the Lemurs and even in the Reptiles, attaining a high stage in the Monkeys, and gradually specialised in a different direction in man. The whole member takes part in the action here and not, as is commonly believed, its terminal segment only. In monkeys the fingers are slender, long, and recurved; the thumb is short and also slender; the trapezo-metacarpal articulation which supports it permits thus the two movements of oblique adduction and abduction, or of opposition. Nevertheless, this articulation in its movements is rude. It is a kind of tongs with curved branches, an organ made for encircling the limb of a tree, and only secondarily to grasp small objects and break them into pieces. On the other hand, the radius is capable of a movement of rotation on the cubit of about eighty degrees, and the articulation of the shoulder is very mobile. In the Anthropoids the rotation of the radius rises to one hundred and sixty degrees about, and the scapulo-humeral articulation increases still more in mobility. But the hand undergoes no improvement. In man there is no notable change either in the hand or in the rest of the member, but all has become pronounced and has more precision; a certain simian fold of the palm of the hand has disappeared showing a marked independence of the index finger. The hand is an organ of prehension, an organ of exploration and of touch, and also an instrument.

It has been said that man alone possesses a true hand and that owing to it he can manufacture for himself tools. This is an error. The differences which it presents as compared with the hand of the most favored monkey in this respect, are only differences of kind. The faculty which enabled our prehistoric ancestors to manufacture the hatchets of St. Archeul, then to discover cleavage by repercus- 
sion and the art of edge-making, was less the hand than the intelligence which directed the hand. The great dexterity which the human hand has acquired, for example, in playing on the violin or the piano or in the adjustment of the screw of a microscope, is the fruit of experience and intelligence combined. In fine, the point of departure of the hand was an adaptation to arboreal life, its point of arrival an adaptation to intellectual life.

The differences which are now to be noticed are more decisive. They relate to the disappearance of the snout, the consequent reduction of the nasal fossæ, accompanied by the effacement of the last vestiges of the limbic lobe, and especially to the reduction of the maxillary apparatus, caused no doubt by the transference and localisation in the hands of the function of prehension, before divided between the hands and the mouth. The orthognathism of man's face, which stands in such marked contrast to the frightfully bestial face of the Anthropoids, is the result of this.

We have reserved for the last the group of differences presented by the other parts of the skull, because they result from the association of three orders of adaptations or influences on which a preliminary word is necessary, viz.:

I. The volume of the brain which, in its increase from the Anthropoids, or some analogous type, to man, exerts a strong pressure on all sides, elevates the vault of the skull, depresses its base, tips the frontal bone forwards, the occipital bone backwards, and adapts everything to its wants; (2) the adaptation to the bipedal attitude, which takes place by the overthrow backwards of the occipital bone, above mentioned, where the occipital foramen, which in the Monkeys and other mammals is at the back of the base of the skull and in man is in the centre of it, is transported from backwards forwards ; (3) atrophy of the facial part of the skull of which we have just spoken. One of the consequences of this atrophy, associated with the development of the anterior lobe of the brain and of its frontal compartment, is the formation of the forehead, one of the distinctive traits of man. ${ }^{1}$

${ }^{1}$ At the other extremity of the face the chin also is a human character. 
I have set forth at length the mechanism of this transformation of the animal skull into the human skull in L'Anthropologie. ${ }^{1}$

All in all, then, we are led by our rapid review of the craniological and craniometrical characters to the following conclusion. There exist among the Primates three widely different types of skull; first, that of the Lemurs, which is that of the other mammals generally; secondly, that of the Monkeys, both of the Old and of the New World, including the Anthropoids,-a type of skull which is intermediate between that of the Lemurs and that of man; and thirdly, a type which is sui generis-that of man. Accordingly, an abyss which nothing fills separates man from the Monkeys. On the other hand, here and there, in isolated characters, some Monkeys, now a Cebus, now a Pithecus, now an Anthropoid, and usually always the young, present some point of resemblance with man.

There are still other differences to be noted, but of less interest. Thus, we have characters of growth; for example, sutures which close earlier or later. We have also simplifications of organs or secondary harmonical adaptations, such as the decrease of the usual number of nineteen vertebræ in Monkeys to seventeen in man; the arrangement of the summit of the sacrum and of the coccyx in consequence of the disappearance of the tail both in the Anthropoids and in man; the atrophy of the laryngal sacs, which have become unessential after the acquisition of language; the disappearance of the auditory bulla of Lemurs, progressive in the Monkeys and the Anthropoids and replaced in man by the mastoid cells, etc., etc. Other differences are the particular adaptations to the life and the new habits of man, such as certain modifications of the condyles and of the articular surface of the mandible, absolutely acquired, and certain characters in the structure of the molar teeth, on which I must dwell.

I wish to speak, not of the canine teeth, which are less voluminous in man, but of the tubercules or cusps of the superior and inferior molars. Like the pelvis and the union of the sacrum and

${ }^{8} \mathrm{P}$. Topinard. "La transformation du crâne animal en crâne humain," in L'Anthropologie. I89ז. P. 649 . 
the coccyx, the fundamental types of these molars join man and the Anthropoids together in a common group, and distinguish them conjointly from the Pitheci, in which the corresponding types are entirely different. Their construction is as follows : Above we have a quadricuspidate type with an oblique crest separating the fourth or postero-interior tubercle, from the three others. Below we have a quinquecuspidate type, arched, with three external and two internal tubercules. But here is the extraordinary fact. In man and not in the Anthropoids, two new types of which we can follow the gradations, take the place of these very frequently: one above tricuspidate by the disappearance of the fourth tubercle, the other below quadricuspidate like a cross. Professor Cope, who has studied the first of these accidental types, the tricuspidate, sees in it a reversion to the lemurine type. For my part I take it to be an adaptation to the alimentary system of man, a perfective character in process of formation, one of the traits of the man of the future. Even in the absence of other proofs, and others do exist, this fact shows that man is still in process of evolution, and that if he is progressing by his brain and its functions, he is also advancing and being transformed in other parts.

But I must hasten to conclude. Of the differences we have discovered, some are equivalent to intervals of an order or suborder, others to intervals of a family, others to intervals of a genus. It is incumbent upon us to weigh the physiological value of each, to set them off one against the other, and to obtain their approximate mean. The brain and the skull are of most importance; the attitude comes next, the hand, the teeth, the muscles, and viscera come last.

Briefly, then, my conclusion is : ( 1 ) that the Cebidæ, the Pitheci, and the Anthropoids, all of them arboricole creatures by equal rights, cannot be separated from one another, but that the same name of Monkeys properly applies to them as much as does that of "quadrumane" given by Cuvier; (2) that in this group the Anthropoids have reached the highest stage of evolution and are consequently less remote from man; (3) that the distance of the monkey group from man is on an average greater than that which 
commonly separates families and a fortiori genera, and less than that which separates orders; (4) that this distance is about equal to that which separates the Monkeys from the Lemurs; (5) that man, therefore, forms a suborder in the order of Primates as shown in the following table:

ORDER OF PRIMATES.

First suborder: Man.

Second suborder : Monkeys $\left\{\begin{array}{l}\text { First family : Anthropoids. } \\ \text { Second family: Pithecidæ. } \\ \text { Third family : Cebidæ. } \\ \text { Fourth family: Arctopithecidæ. }\end{array}\right.$

Third suborder : Lemurs.

To sum up, the Lemurs of this classification are simply the starting-point of the Primates. The Monkeys are animals adapted to arboreal life and perfected to this end. Man is an animal adapted to intellectual life and perfected towards this end.

Is it a consequence of this schematic statement of the intervals separating present man from the other present Primates that man is descended from the highest Monkeys, the Anthropoids? The question is prejudged, but not settled. Suppose we have two phyla or types. Both become differentiated into secondary branches or types. The latter come into different environments and different modes of life; they adapt themselves thereto and evolve separately. Some diverge from each other, others approach nearer to each other, others go along side by side. This is what is called resemblance by convergence and difference by divergence. Therefore resemblance and dissimilarity are not a criterion. This same view is applicable to human races. Two or three may have originated apart at remote epochs and have come to resemble each other by convergence. The unity or the plurality of the origin of the human races is not a solved question.

Be that as it may, in the hypothesis of a single origin two opinions are tenable. One, which Professor Cope defends, is based upon palæontological evidence, and makes man descend directly from certain Eocene Lemurs, through a series of precursors doubtless, who have lifted him up to his present state, but of which we have 
as yet no direct evidence. The other, which is based upon existing species, makes man descend directly from the Pitheci or the Cebidæ, or, which is more probable, from the Anthropoids.

This is what I wrote on the subject three years ago, with regard to one character. I modify the phraseology slightly: "From my studies on the cusps of the molars and premolars of Primates I am disposed to conclude that the type of Maki and Tarsius, the first group of Lemurs, has engendered on the one hand that of Lori, Propithecus, and Galago, the second group of Lemurs, and on the other hand that of Indri, the third group of Lemurs; that the type of Lori, etc., has given the Cebidæ, and that of Indri the Pitheci, from which would have issued the common fundamental type of Anthropoids and of man." 1

What is certain is, that man by all of his characters is descended from some Primate. The brain, the hand, and all that relates to his way of standing, with the exception of the foot, are proofs of it.

But from what branch and in what epoch was the initial shoot thrown off? That is a question which it is wise to reserve for a future time. We should not forget that families and genera of Primates must have existed which have now utterly disappeared, and that the present types may be only descendants of others of which we know nothing.

The comparison between man and the other animals is not restricted to morphological characters. If anthropology gives them the preference, the reason is that they can be got at, analysed, and weighed with great precision, and that they faithfully reflect the functional characters, in virtue of the principle that the "function creates the organ." The proper complement of the preceding review, therefore, would be the examination of the physiological characters and particularly of those which relate to the really characteristic organ of man-his psychological characters. But that would carry us too far.

1P. Topinard, "De l'évolution des molaires et premolaires chez l'homme," in L'Anthropologie, r892, p. 709 . 
We should have to show, if we entered on this subject, that man has the same functions as animals, slightly modified here and there, the same general needs, the same modes of satisfying them, the same sentiments, desires, impulses, and motives, the same reflex actions, with or without the intervention of the sensorium. We should have to show the psychical faculties that are brought into play between sensation and action, isolated and rudimentary in this or that lower or higher animal, less isolated and more marked in others, forming associations in greater or less numbers in one class, and attaining a remarkable degree of development in another, as in the elephant, the dog, and the ape, but arriving at their highest degree of differentiation and complexity in man when the volume of the brain and its convolutions have reached their maximum. We should have to show in these animals the powers of curiosity, attention, observation, reflexion, determination, the sense for cause and effect, memory, and incontestably ideas, for which only the formula is lacking. The studies which have been pursued on this subject in England for many years teem with examples. It would be our task to show in the Apes malice, imitation, the need of play, the spirit of examination, of sympathy, of defiance, the need of talking, of hearing and being heard, the sense for assistance in raising a large stone or in crossing a river, the sense of mutual understanding for making forays or for self-defence, the sense of common utility in disposing sentinels, who are punished when they permit the band to be surprised, etc. Is there reason to be astonished if one of these animals, having acquired by dint of hard efforts articulate language which helps him to fix his memories and ideas and simplifies these operations, or by having become gradually more precise in his acts of reason, more careful in his acts of will, more highly conscious of himself, more inventive in satisfying his daily needs, - is it to be wondered at that he should have created for himself new and peculiar needs, even physical in character, and that little by little he should have lifted himself up to the level of the æsthetic sense, the spirit of philosophical inquiry, and the love of truth?

True, the volume of the brain and its convolutions are far from explaining all this. But there are other morphological factors of 
mental power: for example, the number, size, and relation of the cerebral cells, and particularly their intrinsic qualities, which still vary so much with individuals that, in our species, a scale running from ten to a thousand, I should say, could be established for them. Think of the psychological difference between the extinct primitive races and the higher races of to-day, and in these last between men who think and act in a totally vegetative fashion, and the leading intellects of the nineteenth century!

Finally, from the morphological characters which we have summarised, and the psychological characters which we have alluded to, this fundamental truth emerges, which must be distinctly emphasised : that man, perfect as he may appear to us, is still not a being apart in nature, but that he is by his whole organisation continuous with the other zoölogical species, that he is connected with them by a multitude of characters, if not by all, and that the differences are only relative differences of degree in an evolution in the same direction, augmentations and diminutions of organs or of parts of organs more or less utilised, modifications of development, primary adaptations to new habits and modes of life, secondary harmonical adaptations, etc. It is that man is an animal by the same right as every other vertebrate, mammal, and primate, and that anthropology properly so called is merely a chapter of zoölogy.

No, man is not a creature apart in creation, and it is rather a concession to the spirit of the times than a protest against the idea of our animality, that some naturalists have proposed to place apart all that concerns the intellect, and make of man a fourth kingdomthe human kingdom. De Quatrefages, who advanced this view after the precedent of Isidore Geoffroy St. Hilaire, averred none the less that "man was only an animal, nothing but an animal"the rational animal of Aristotle and Linnæus, Franklin's tool-making animal.

Certainly, man has been favored by evolution. The organ which alone really characterises him appears from its first progress in the fishes to have been predestined for its future rôle. In the birds the hemispheres have already much importance, but their development is arrested. In the various orders of mammals, the 
brain has more progress to show, but does not go so far as to overshadow adaptations in other directions. Evolution furnishes here various types, all of them highly harmonious and highly adapted to the habits, but relating to muscular force, rapidity of progression, or elegance of form. In the elephant the cerebral organ and its faculties attain a certain superiority, but the enormous size of the animal and the exigencies attending on the needs of its tremendous body prevent its advancing beyond this stage. In the order of the Primates alone, evolution, modest in its beginnings but always properly directed, takes a happy leap and attains its highest stage in man. But the favored lot of man, that good luck of which the acquisition of language was certainly the determining cause, has not at all deprived him of his animality.

Whatever may be said to the contrary, man forms an integral part of that great tree, which took its birth untold centuries ago in the moners, which grew and waxed great throughout the ages, and which gave out the boughs called Worms and Crustacea, Reptiles and Mammals, and those others called Carnivora and Primates, from which have issued so many innumerable branches, among them man. As Monism would have it, this tree is one and continuous in all its parts. Some of its branches are descendent, others ascendent, others parállel or divergent (retrograde, progressive, parallel, and divergent evolution). Many have vegetated, or have arrived at the goal of their evolution, -or of their potencies, as we might say, -and have died, leaving behind them no trace. Many have survived without notable alteration, or have perfected themselves and multiplied.

The extinct and now existing species are the extremities of these boughs and branches at the different epochs of the world. Man is merely one of them, having appeared in the Pliocene or Quaternary epoch at the summit of some ascending branch. All these species have thus the same origin, at the expense of previously existing species; all have risen by a similar mechanism, have evolved according to the same laws, and have, or will have, the same destinies : to bear witness to the splendor of nature and to disappear, leaving or not leaving a posterity. 
I shall sum up these laws or factors of evolution, as follows :

I. The law of spontaneous expansion or proliferation of living matter, first cause of evolution.

2. The law of spontaneous variation of living matter; whence result, with the concurrence of other laws, the multiplication and differentiation of forms, the division and specialisation of labor.

3. The law of reaction of living matter (irritable or sensible) in the presence of external or internal stimuli; whence results the law of conformity of organs to their ends or adaptation to the environment and conditions of life.

4. The law of heredity or of resemblance; whence result, with the concurrence of favorable circumstances, the accumulation and fixation of habits and of characters insensibly developed.

5. The law of the survival of the best equipped and the best adapted.

This evolution is effected through individuals and is furthered by their free competition, their struggle against the environments, circumstances, and conditions of existence. Those most favored by some spontaneous variation, those which know best how to utilise their advantages, which know best how to conform to circumstances, the best adapted and strongest, the nimblest, those most obedient to the injunctions of nature, survive and multiply.

This struggle operates only indirectly among species, although the general result of it is the modification of their type; it operates through individuals. It is they to which this or that variation, this or that adaptation, this or that particular circumstance gives survival and predominance. The instinct of conservation, the necessity of satisfying personal needs, the desire to enjoy life to the full, all exalts individuality. For the individual the world is what he perceives-his series of impressions from his earliest infancy, the memory of his acts, of his struggles, and of his sufferings. His sensorium is the focus in which all is gathered. He is perforce subjective. He is by sensibility and by logic egocentric. I first, others afterwards. What touches him has his first consideration; what touches others has it not till he is moved to it by impulses, by interest, or by pleasure. If others succumb it is a void for him; if 
they suffer he attempts to realise their sufferings, shares them, and will even seek to assuage them, often with the ulterior thought that in similar circumstances they will render to him a like favor. If he makes sacrifices, if he loves his companion, if he takes care of his children, he is recompensed for it by the pleasure which he derives therefrom. The more powerful his individuality is, the more powerful is he. The more energy the individual has, the more he affirms himself, the more his life is fulfilled, the happier he is, and the more he shares and assists in the progress of the group to which he belongs.

There are, moreover, two beings in the individual: one, the initiative element, which reasons, wills, and is the fruit of his personal education; the other, the routine element, which is the product of habits acquired by his ancestors, repeated and established by accumulated heredity-habits of family, race, species-organic, motor, and psychical habits. To the last are due the greatest number of the acts of life, our impulses and so-called innate ideas; the first intervenes only occasionally. As I stated in my memoir of 1893 above cited, as Dr. Paul Carus has well expounded in his book Le probleme de la conscience $d u$ moi, and as the majority of physiologists to-day admit, all acts are more or less reflex and co-ordinated beforehand for every aim that is to be attained. The centre of reflex action in the vertebrates is in the spinal cord or in its intracerebral prolongation. In one category of acts an external or internal peripheral impression is the origin of the action; in a second category the excitation comes from the brain and is a sensation or a sentiment, in both cases unconscious or obscurely conscious; in a third, the excitation still comes from the brain but the sensation or the sentiment is entirely conscious, gives rise to a ratiocination, a decision, a given order. The two first categories, accordingly, are more or less automatic, the second being so both by the act and by the incitation. They answer to what are called instincts. These may be divided into instinctive sentiments and instinctive acts, and have as common characters on the one hand production without the intervention of reflective volition, and on the other ancestral origin. 
Now instincts are the rule in animals and the commonest case in man. It is they that control individualism, that bring back incessantly and unconsciously to man his antecedents, that have as their object what is useful and as their raison d'être submission to the exigencies of struggle and to the higher laws of nature. Is the third category of acts, those which take place as the result of deliberation, commoner? Do they carry with them a vestige of altruism? Are they able in certain circumstances to modify or to annul the instincts? These are questions which we cannot examine without encroaching on the subject of social man, which lies beyond our present task.

Anthropology, in fine, as long as it does not occupy itself with peoples, civilisations, and social constitutions, discovers in man an animal only, to which it applies the general truths which natural history and particularly zoölogy teach it. For anthropology there exist only differences of form and degree between invertebrates and vertebrates, and between the different classes, orders, families, and species of these. The laws which control one rule the others. The mechanisms, theories, and doctrines which apply to animals apply to man, and vice versa. As they have the same substance and are of the same origin, so they have the same destiny. From the irritability of a moner to the sensibility of a mollusk endowed with a nervous system; from the sensibility of an insect possessing the rudiment of a brain to the sensibility of the horse, of the ape, or of man, who is provided with a centralised brain with highly differentiated sensibilities, anthropology sees degrees only. From the consciousness entirely mechanical of the moner, distinguishing what is beneficial from what is injurious to it, to the rudimentary consciousness of the fish or the reptile, to the consciousness of the dog or the elephant, and lastly, of man, it still sees only degrees. A professor in a Catholic university, whose name I may withhold, conceded, in conversation with me one day, the doctrine of transformism. "Your doctrine does not disturb in the least the teachings of the Church," he said ; "we will give you the body if you will leave us the soul." "Very well," I answered, "but what do you understand by the soul? Do you admit its existence in animals?" "I do," he replied, 
"but as a less developed soul." That professor was an intelligent man. Such is, in fact, the soul in man; such it is in different degrees of evolution in animals. What is true of man is true of animals, and vice versa.

There are two methods of considering nature-one from our own or the human point of view, and the other from the point of view of Nature herself. For Nature, the spectacle which we offer is that of a busy hill of ants which swarm hither and thither with no aim beyond their present life. For Nature, the species succeed each other with no other motive than to bear witness to their marvellous proliferation. For Nature, everything that can take place in her broad bosom does take place; the elements combine, dissociate, meet again, forms succeed forms, disintegration follows integration, equilibrium is fleeting, there is no end, the movement is perpetual. Man in this whirlpool, like all the rest, is but a grain of sand; he has to think only of himself. He may fashion for himself ideals, he may assign a goal to his progress, he may impose a programme on his beliefs, he may close his eyes to reality. Well and good! But the thinkers that exercise their ingenuity in adapting him to the conditions of his existence, in creating for him a world of his own, in laying down the rules for his conduct, and in seeking foundations for it least open to attack, must not forget that his only cherished aim is his own happiness.

Paul Topinard.

Paris, France. 